\title{
Analysis of Class III Peroxidase Genes Expressed in Roots of Resistant and Susceptible Wheat Lines Infected by Heterodera avenae
}

\author{
Ester Simonetti, ${ }^{1}$ Pasqua Veronico, ${ }^{2}$ M. Teresa Melillo,, ${ }^{2}$ Ángeles Delibes, ${ }^{1}$ María Fe Andrés, ${ }^{3}$ and \\ Isidoro López-Braña ${ }^{1}$ \\ ${ }^{1}$ Departamento de Biotecnología, ETS Ing. Agrónomos, UPM, Madrid, E-28040, Spain; ${ }^{2}$ Istituto per la Protezione delle \\ Piante, IPP, CNR, 70126 Bari, Italy; ${ }^{3}$ Instituto de Ciencias Agrarias, CCMA, CSIC, Serrano115 dpdo, Madrid, E-28006, Spain
}

Submitted 3 February 2009. Accepted 8 May 2009.

\begin{abstract}
The response of resistant wheat-Aegilops ventricosa introgression line H-93-8 and its susceptible parent, Triticum aestivum H-10-15, to Ha71 Spanish population of Heterodera avenae was studied to determine the changes in peroxidase gene expression during incompatible and compatible wheat-nematode interactions. Twenty peroxidase genes were characterized from both 211 expressed sequence tags and 259 genomic DNA clones. Alignment of deduced amino acid sequences and phylogenetic clustering with peroxidases from other plant species showed that these enzymes fall into seven different groups (designated TaPrx108 to TaPrx114) which represent peroxidases secreted to the apoplast by a putative $\mathrm{N}$-terminal peptide signal. TaPrx111, TaPrx112, and TaPrx113 were induced by nematode infection in both genotypes but with differing magnitude and timing. TaPrx112 and TaPrx113 groups increased more in resistant than in susceptible infected lines. In addition, in situ hybridization analyses of genes belonging to TaPrx111, TaPrx112, and TaPrx113 groups revealed a more intense signal in cells close to the vascular cylinder and parenchyma vascular cells of resistant than susceptible wheat when challenged by nematodes. These data seem to suggest that wheat apoplastic peroxidases, because of their different expression in quantity and timing, play different roles in the plant response to nematode infection.
\end{abstract}

The cereal cyst nematode (CCN) (Heterodera avenae Woll.) is the most widely distributed and damaging species on cereals cultivated in less temperate regions. This nematode species has been detected in many countries, including Australia, Canada, South Africa, Japan, most European countries, and Asia, and it is responsible for yield losses in wheat of up to $30 \%$. The CCN

Nucleotide sequence data are available under the following accession numbers: TaPrx111-A, EU542600; TaPrx111-E, EU595572; TaPrx11-H, EU595575; TaPrx111-L, EU595573; TaPrx112-A, EU595569; TaPrx112-C, EU567314; TaPrx112-D, EU595568; TaPrx112-M, EU595567; TaPrx113A, EU595576; TaPrx113-B, EU595577; TaPrx113-F, EU595578; TaPrx114A, EU595579; TaPrx114-B , EU595580; TaPrx114-C, EU595581; TaPrx108, EU595582; TaPrx109-A, EU725463; TaPrx109-B1 to B5, EU725464 to 68; TaPrx109-C, EU725469; TaPrx110-A, EU725470; TaPrx110-B, EU725471; and TaPrx110-C, EU725472.

Corresponding author: I. López-Braña; E-mail: isidoro.lopez@upm.es

* The $\boldsymbol{e}$-Xtra logo stands for "electronic extra" and indicates that three supplemental tables are published online. induces syncytial feeding sites in the roots of its hosts. Infective second-stage juveniles (J2s) enter the plant roots at the level of the differentiation zone and penetrate intracellularly toward the vascular cylinder. Here, they select and pierce with their stylet a single cell where they release oesophageal secretions. In the following hours, the affected plant cells start to develop the feeding structures (Das et al. 2008). The central vacuoles disintegrate into several small vesicles, nuclei enlarge, and the number of cytoplasmic organelles increases. Cell walls are dissolved locally along plasmodesmata, thus giving rise to the formation of a syncytium. Approximately 2 weeks after infection, the nematode reaches maturity and is associated with a syncytium, typically including a great number of cells (Golinowski et al. 1996).

Many different methods are available to control nematodes such as chemical, cultural, genetic (resistance/tolerance), and biological control and their effects are aimed at decreasing population densities below damage thresholds so as to maintain or reach an attainable yield. One of the most effective control measures is the use of host resistance, which is defined as the reduction in the multiplication of the nematode in the presence of resistant plants. Globally, this is acknowledged as one of the most cost effective, environmentally sustainable, and accessible methods of controlling $\mathrm{CCN}$. As reviewed by Nicol and Rivoal (2007), there has been considerable progress in identifying resistance to $H$. avenae, with all reported genes to have a major effect (i.e., controlled by a single dominant gene), making their use in a breeding program very amenable. These sources have been found predominantly in wild relatives of wheat in the Aegilops genus, with six of the eight named Cre genes for $H$. avenae resistance coming from four Aegilops spp. Most of these genes have already been introgressed into hexaploid wheat backgrounds for bread wheat breeding purposes (Delibes et al. 1993, Eastwood et al. 1994; Ogbonnaya et al. 2001; Romero et al. 1998; Seah et al. 2000). However, the effectiveness of these Cre genes depends on the nematode pathotype in conferring total or partial resistance to different $\mathrm{CCN}$ populations. For example, it has been demonstrated that Cre 3 has the greatest impact on reducing the Ha13 Australian population, followed by $\mathrm{Cre} 1$ and $\mathrm{Cre} 8$ (Safari et al. 2005), but it is susceptible to European pathotypes (Montes et al. 2008; Rivoal et al. 2001). In contrast, the dominant resistance gene Cre2, which confers a high level of resistance to several European populations of $\mathrm{CCN}$, including the Ha71 Spanish pathotype used in this study (Delibes et al. 1993), was ineffective against the Australian pathotype (Ogbonnaya et al. 2001). In a previous work, the efficacy of Cre genes against Spanish patho- 
type Ha71 was rank-ordered as Cre $1 \geq$ Cre $4 \geq$ Cre $5 \geq$ Cre $2 \geq$ Cre $7>>$ Cre $8>C r e 3>$ Cre 6 (Montes et al. 2008).

Plants defend themselves from nematodes using a variety of mechanisms, including rapid induction of localized necrosis at the site of infection (the hypersensitive response [HR]), increased expression of defense-related proteins, production of antimicrobial compounds, lignin formation, and the oxidative burst. The nature of the plant genes switched on or off during the nematode-host interaction is a subject of great interest because some of the products of these genes are directly responsible for promoting nematode parasitism or for fending off the nematode attack. Moreover, the timing in the surveillance system of receptor molecules that can recognize elicitor molecules of pathogen origin is fundamental for the host response and is functional against a wide spectrum of pathogens (Nürnberger et al. 2004). Following this initial recognition, multiple biochemical pathways are activated and lead to a cascade of reactions, ultimately resulting in the formation and accumulation of secondary metabolites which help the plant to overcome the parasite (Zhao et al. 2005).

Plant class III peroxidases (PRX) have been proposed as key regulators of the level of extracellular $\mathrm{H}_{2} \mathrm{O}_{2}$ and as producers of the extremely reactive oxygen species (ROS), hydroxyl $(\mathrm{OH} \bullet)$, and hydroperoxyl $(\mathrm{OOH} \bullet)$ radicals (Bindschedler et al. 2006; Bolwell et al. 2002), depending on whether the peroxidative (catalytic) or the hydroxylic cycles of the enzyme are operating (Kawano 2003; Passardi et al. 2005). During the hydroxylic cycle, peroxidases use mainly the superoxide anion $\left(\mathrm{O}_{2}^{-}\right)$to generate $\mathrm{OH} \bullet$ while, in the peroxidative cycle, these enzymes catalyze the reduction of $\mathrm{H}_{2} \mathrm{O}_{2}$ by oxidizing various substrates. PRX, by using both these cycles, are known to participate in many different plant processes from germination to senescence (i.e., auxin metabolism, cell wall elongation, and stiffening) or protection against abiotic and biotic stresses (Cosio et al. 2009; Kawano 2003; Liu et al. 2005).

Current models of plant defense responses include peroxidase-generated radicals and ROS as catalysts of covalent cellwall modifications (Østergaard et al. 2000; Ros Barcelo 1995) as well as signals for cell-death reactions (Passardi et al. 2005). $\mathrm{NAD}(\mathrm{P}) \mathrm{H}$, indoleacetic acid, and saturated fatty acids represent the most important substrates oxidized by the peroxidase-mediated pathway (Hirada et al. 2001). In this regard, the peroxidases appear to act as bifunctional enzymes that can oxidize various substrates in the presence of $\mathrm{H}_{2} \mathrm{O}_{2}$, but also generate $\mathrm{H}_{2} \mathrm{O}_{2}$. Despite the correlative evidence for the involvement of peroxidase activity with pathogen resistance, regulation of PRX during nematode infection, on the isoenzyme basis, is largely unknown because many of these isoenzymes are simultaneously expressed in plants in response to pathogen infection and, moreover, some of them work as antioxidant enzymes (Zacheo et al. 1997). Involvement of peroxidases in wheat defense was suggested by selectively induced expression of the pox 2 peroxidase gene in leaves of hexaploid wheat (Båga et al. 1995) as well as other peroxidase genes in diploid wheat, Triticum monococcum, when challenged by powdery mildew fungus (Liu et al. 2005). In addition, hydrogen peroxide production is a known response of host plants to root-knot (Das et al. 2008; Melillo et al. 2006) and cyst (Waetzing et al. 1999) nematode invasion.

In previous studies, findings obtained by our group (Andrés et al. 2001; Montes et al. 2003, 2004) demonstrated that cyst nematode infection enhances PRX, esterase, and superoxide dismutase activity in wheat roots carrying $\mathrm{Cre} 2, \mathrm{Cre} 5$, or $\mathrm{Cre} 7$ resistance genes. The highest response was found in the PRX system with an increase in both cationic and anionic isozymes. Therefore, to understand the precise role of each individual isoform in planta, it is imperative to study its function, and its regulation following nematode infection.
The objective of the present study was to asses the involvement of peroxidases in the defense response against nematode infection. We describe the expression patterns of these isoforms at the level of transcript accumulation and localization in resistant (H-93-8) and susceptible (H-10-15) wheat lines challenged by CCN. Indeed, although, in some cases, spatial and temporal localization or indirect evidence might indicate the involvement of peroxidases in specific mechanisms (Andrés et al. 2001), their in planta transcription has never been clearly characterized.

The data presented here suggest that a number of PRX transcripts might play a role in the constitutive and inducible defense mechanisms, as reported in other host-pathogen interactions (Liu et al. 2005; Schweizer 2008). Moreover, these findings provide a comprehensive response of accumulation of PRX gene transcripts and might help to understand their involvement in wheat roots challenged by $\mathrm{CCN}$.

\section{RESULTS}

TaPrx genes and predicted proteins identified from nematode-infected roots.

Root cDNAs from H-93-8 at 4 and 7 days after nematode inoculation were used to identify the PRX genes involved in the response to the pathogen attack. Rapid amplification of cDNA ends (RACE)-3' and RACE-5' products were aligned in order to obtain complete transcript sequences. Specific primers were designed from low-homology areas of these peroxidase transcripts to amplify genomic DNA belonging to H-93-8 and its parents, T. aestivum (H-10-15), T. turgidum (H-1-1), and Aegilops ventricosa (AP-1). Sequence similarity analysis showed that the 470 sequenced clones (211 expressed sequence tags [EST] and 259 genomic) represented at least 17 peroxidase genes and three pseudogenes (Fig. 1; Table 1), all present in the four tested lines. Alignment of these peroxidase genes revealed changes in length and nucleotide sequence, in particular, in 5' (38 to $100 \mathrm{bp}$ ) and $3^{\prime}$ (91 to $567 \mathrm{bp}$ ) untranslated regions (UTR) (Fig. 2).

The 20 TaPrx predicted protein sequences showed well-conserved B, D, and F domains, also found in Arabidopsis (AtPrxs) and rice (OsPrx). The phylogenetic tree generated by encompassing complete PRX amino acid sequences from wheat $(n=17)$, rice $(n=10)$, barley $(n=2)$, and Arabidopsis thaliana $(n=1)$ is represented in Figure 3. The PRX sequence of Marchantia polymorpha (Mp-Q8H958) was used to root the tree because it provided the maximum sequence length when compared with other outgroups. Clusters were strongly supported by bootstrap values. Six clusters, designated TaPrx 108 to TaPrx114, were found: three members fit in the cluster TaPrx111 (TaPrx111-A, TaPrx111-E, and TaPrx111-L), four in TaPrx112 (TaPrx112-A, TaPrx112-C, TaPrx112-D, and TaPrx112-M), three in TaPrx113 (TaPrx113-A, TaPrx113-B, and TaPrx113-F), three in TaPrx114 (TaPrx114-A, TaPrx114B, and TaPrx114-C), one in TaPrx108, and three in TaPrx109 (TaPrx109-A, TaPrx109-B, and TaPrx109-C). TaPrxs exhibited an identity different from the most similar selected rice PRX at protein levels ranging from $77 \%$ (OsPrx110 with TaPrx108) (Table 1) to $85 \%$ (OsPrx74 with TaPrx109-A). The closest homologue for clusters TaPrx112 and TaPrx113 came from barley (Hordeum vulgare peroxidase 1 precursor showing $85 \%$ identity with TaPrx112-D and TaPrx112-A and 96\% with TaPrx113-F) (Table 1). The homology among the 17 fulllength TaPrx-deduced amino acid sequences ranged from 34 to 99\% (data not shown). Based on isoelectric point (pI) predictions (Table 1), mature proteins represented either acid (clusters TaPrx111, TaPrx113, TaPrx108, and TaPrx109) or basic (clusters TaPrx112 and TaPrx114) isoforms of PRX, with pI 
ranging from 5.51 to 9.00 . TaPrx113-A showed the highest identity to Pox3 (CAA59486, 96\%) (Table 1) and TmPRX1 (AAW52715, 99\%) (Table 1), two proteins deduced from powdery mildew inducible $P R X$ genes isolated from bread wheat (T. aestivum) and $T$. monococcum leaves, respectively. TaPrx112-M was identical to TmPRX3 (Table 1) and showed very high identity to Pox2 (CAA59485, 99\%), another protein sequence deduced from a $P R X$ gene induced by powdery mildew in bread wheat (Båga et al. 1995) (Table 1). Other GenBank peroxidase proteins from different monocot plants (rice and barley) were found to be homologous (more than $72 \%$ identity) to the wheat PRX (Table 1).
Intron structure of wheat peroxidase genes.

The $P R X$ genes present the classical pattern of four exons and three introns shared by the majority of PRX genes (Tognolli et al. 2002). The TaPrxl11 group was also characterized by this pattern (Fig. 2), while the remaining $P R X$ encoding genes consisted of three exons and two introns. Only these two models were found in all analyzed genomic sequences. Wheat introns exhibited a smaller size range ( 81 to $499 \mathrm{bp}$ ) than rice (38 to 9,974 bp), with TaPrx114-A to - $C$ genes showing the largest size (385 to 499 bp) (Fig. 2). Sequences TaPrxl11-H, obtained from line H-10-15, and TaPrx114-C (data not shown) were characterized by the presence of very large introns con-

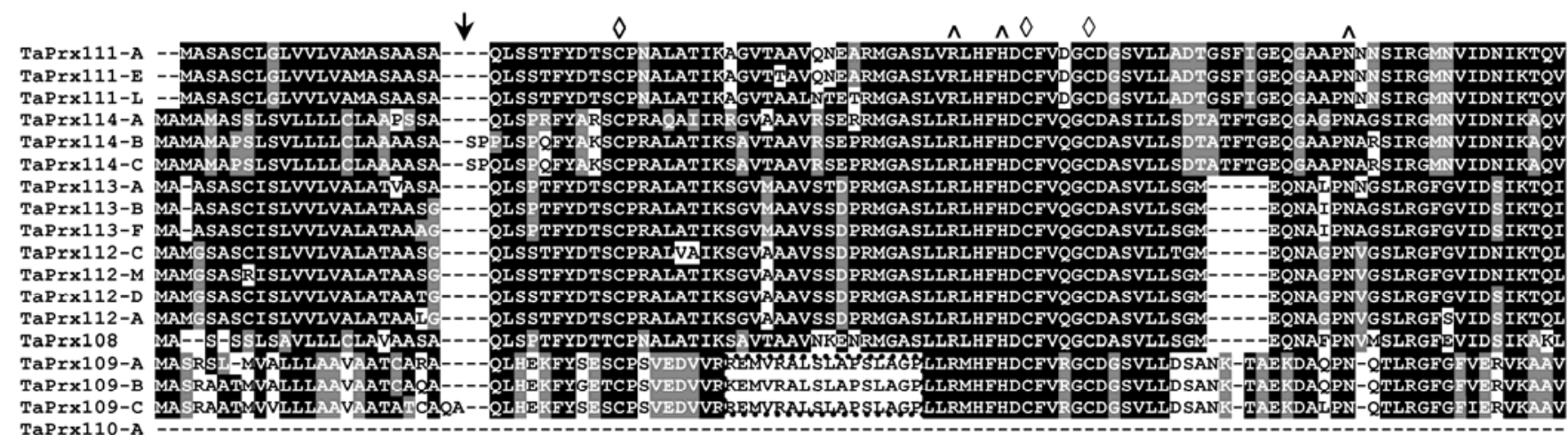

TaPrx110-C

TaPrx110-B

爪

$\uparrow \frac{B}{B}$

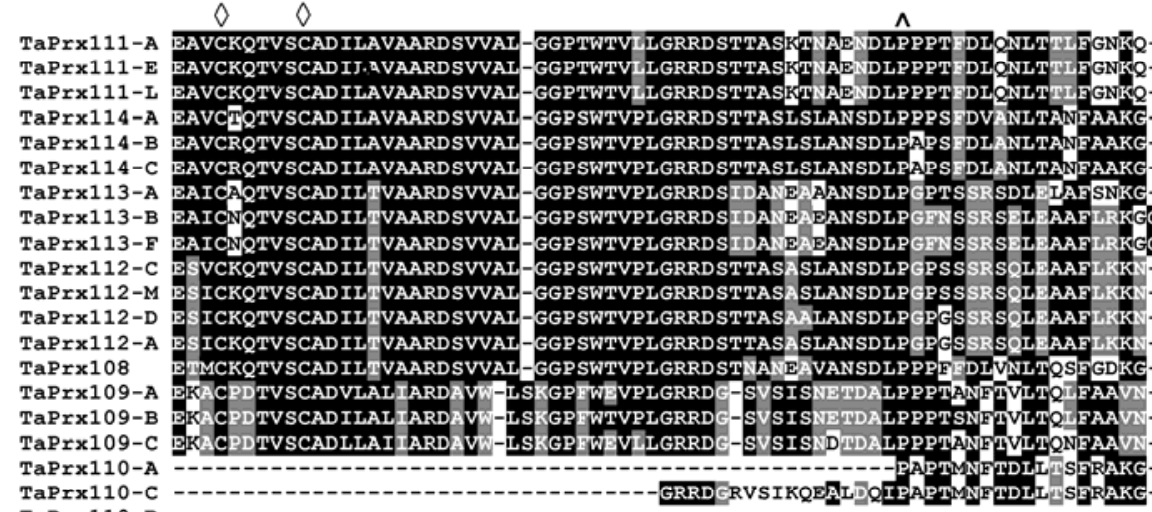

TaPrx110-c

TaPrx110-B

$\mathrm{D}$

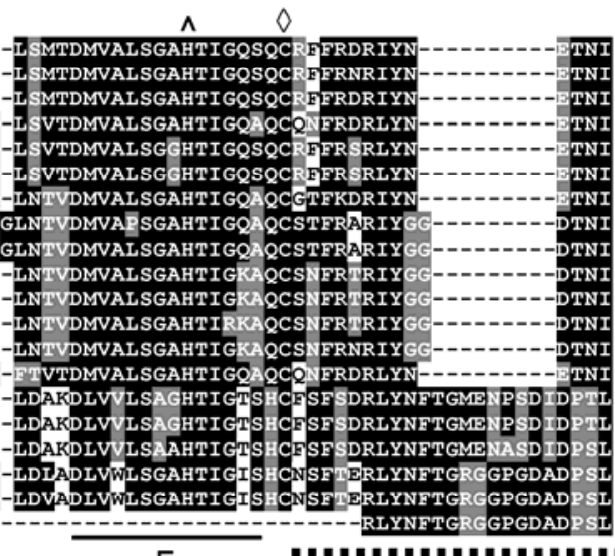

$\mathrm{F}$

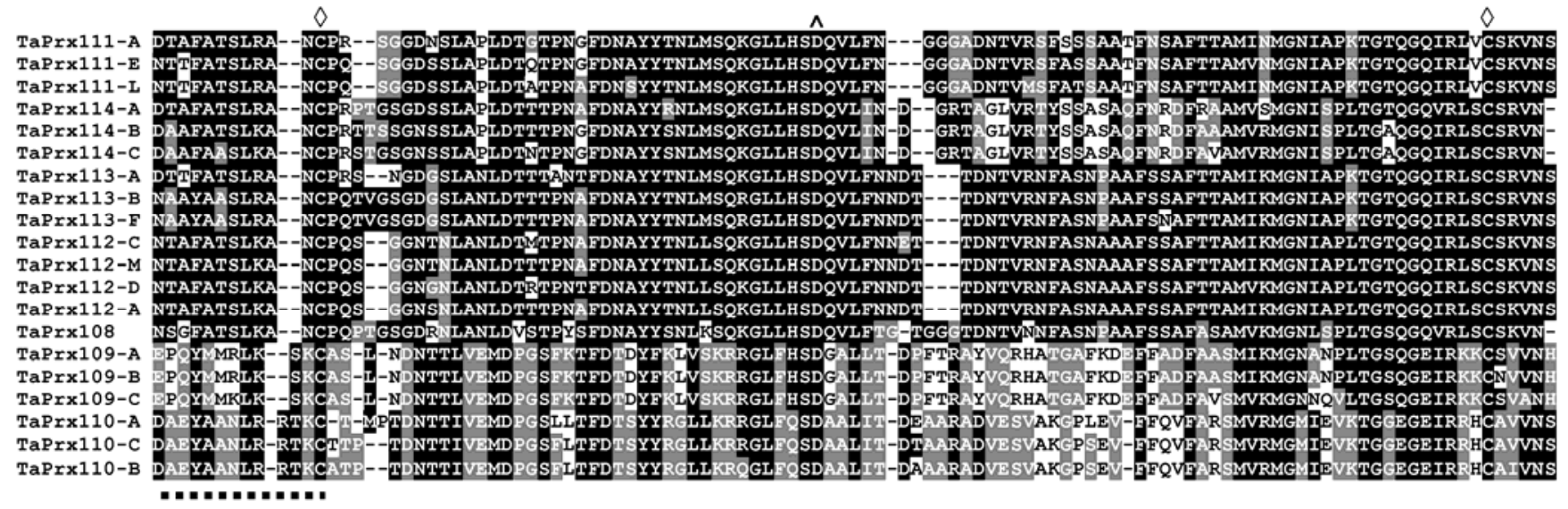

Fig. 1. Multalin alignment of predicted amino acid sequences of wheat TaPrx genes. Gaps introduced for better alignment are shown by dashes. Vertical arrow indicates the separation between putative signal peptides and mature proteins. Horizontal lines represent conserved distal heme-binding (B), proximal heme-binding (F), and central conserved (D) domains of unknown function. A region presumed to be important for determining the specific function (see text) is indicated by a dashed line. Invariable eight-cysteine residues, which form four disulphide bridges, are marked with the diamond symbol. Putative active sites (such as $\mathrm{N}$-glycosylated triplets) are labeled with an inverted ' $\mathrm{V}$ ' symbol on the top of the sequences. A putative monocotyledon-specific motif, present in the TaPrx109 group, is surrounded by a pointed line and two vertical arrows at the margins. TaPrx110 amino acid deduced sequences were truncated at their 5 ' region. 
taining the CACTA E/Spm-like DNA transposon and Mariner/ Tc1 nonautonomous transposon, respectively. The position of introns in relation to the reading frame was totally conserved within all the wheat peroxidases characterized in this study. The nucleotide sequences of introns greatly diverged and almost showed no similarity. The second and third intron contained the classical GT/AG splice sites. In contrast, the processing of the first intron seems to be performed at a nonconsensus GC donor site in TaPrx111, TaPrx112, and TaPrx114 groups (data not shown).

\section{Expression of TaPrx genes is induced by Heterodera avenae infection.}

In order to evaluate the expression of TaPrx genes during the process of wheat infection by Heterodera avenae, transcript levels were monitored by quantitative reverse-transcription polymerase chain reaction (qRT-PCR) 4 and 7 days after nematode inoculation in both susceptible $\mathrm{H}-10-15$ and resistant $\mathrm{H}$ 93-8 lines (Fig. 4). No significant differences were observed between the two methods used for data analysis (quantification assuming efficiencies were equal to two and real-time PCR Miner; discussed below); therefore, only results obtained by Miner analysis are reported in Figure 4.

TaPrx111, TaPrx112, and TaPrx113 groups showed a similar expression pattern in response to nematode infection, reaching their maximum levels at the fourth day postinoculation in the resistant line (Fig. 4). Higher induction of TaPrx112 and TaPrxl13 groups (threefold) was observed in the H-93-8 resistant than in the $\mathrm{H}-10-15$ susceptible line. It is interesting to note that constitutive expression of TaPrxl12 and TaPrxl13 genes in the uninfected $\mathrm{H}-10-15$ line was lower than in the uninfected H-93-8 (3- and 102-fold, respectively). In addition, TaPrxl11 group in the susceptible line showed a different kinetic of transcripts accumulation, with a greater increase of mRNA levels in 7-day infected roots, compared with the resistant one (Fig. 4). These findings suggest that this group of enzymes works in a different manner in compatible and incompatible interactions. The expression patterns of genes in TaPrxl14 and TaPrx109 groups were similar in both interactions and did not show any transcript accumulation following nematode infection (data not shown). TaPrx108 expression was not detected at the RNA level. The expression pattern of TaPrx genes in leaf tissue of both lines showed lower transcript accumulation than in roots (4- to 300-fold) (data not shown), and this behavior was not altered by nematode infection.

Localization of $P R X$ transcripts after nematode infection.

In situ hybridization on serial sections of uninfected and 4day-infected wheat roots was performed to analyze the locali-

Table 1. List of peroxidase genes isolated from Triticum aestivum-Aegilops ventricosa introgression line, H-93-8, resistant to Heterodera avenae ${ }^{\mathrm{a}}$

\begin{tabular}{|c|c|c|c|c|c|c|c|}
\hline Gene name & $\begin{array}{c}\text { GenBank } \\
\text { accession no. }\end{array}$ & $\mathbf{A} \mathbf{A}^{\mathbf{c}}$ & $\mathbf{p I}^{\mathbf{c}}$ & $\begin{array}{l}\text { Molecular } \\
\text { mass (Da) }\end{array}$ & $\begin{array}{l}\text { Signal } \\
\text { peptide } \\
\text { length }\end{array}$ & $\begin{array}{c}\text { Closest GenBank rice or barley PRX } \\
\text { (identity \%) }\end{array}$ & $\begin{array}{c}\text { Closest GenBank Triticum PRX } \\
\text { (identity \%) }\end{array}$ \\
\hline TaPrx111-A & EU542600 & 295 & 5.78 & $31,156.8$ & 21 & Oryzae sativa japonica OsPrx112 (73) ${ }^{\mathrm{d}}$ & T. aestivum $\operatorname{Pox} 1(97)^{\mathrm{e}}$ \\
\hline TaPrx111-E & EU595572 & 295 & 6.08 & $31,200.8$ & 21 & O. sativa japonica $\operatorname{Os} \operatorname{Prx} 112(72)^{\mathrm{d}}$ & T. aestivum Pox1 (99) ${ }^{\mathrm{e}}$ \\
\hline TaPrx111-L & EU595573 & 295 & 5.51 & $31,164.9$ & 21 & O. sativa japonica $\operatorname{OsPrx} 112(72)^{\mathrm{d}}$ & T. aestivum Pox1 (95) ${ }^{\mathrm{e}}$ \\
\hline TaPrx112-A & EU595569 & 291 & 8.44 & $30,433.1$ & 23 & $\begin{array}{l}\text { Hordeum vulgare } \\
\text { peroxidase } 1 \text { precursor }(85)^{\mathrm{f}}\end{array}$ & $\begin{array}{l}\text { T. monococcum TmPRX3 }(98)^{\mathrm{g}} \\
\text { T. aestivum Pox } 2(97)^{\mathrm{e}} \\
\text { T. aestivum WP2 }(95)^{\mathrm{h}}\end{array}$ \\
\hline TaPrx112-C & EU567314 & 291 & 8.44 & $30,503.2$ & 23 & $\begin{array}{l}\text { H. vulgare peroxidase } 1 \text { precursor }(83)^{\mathrm{f}} \\
\text { O. sativa japonica OsPrx114 }(77)^{\mathrm{d}}\end{array}$ & $\begin{array}{l}\text { T. aestivum WP2 }(99)^{\mathrm{h}} \\
\text { T. monococcum TmPRX } 3(97)^{\mathrm{g}} \\
\text { T. aestivum } \text { Pox } 2(97)^{\mathrm{e}}\end{array}$ \\
\hline TaPrx112-D & EU595568 & 291 & 8.82 & $30,514.2$ & 23 & $\begin{array}{l}\text { H. vulgare peroxidase } 1 \text { precursor }(85)^{\mathrm{f}} \\
\text { O. sativa japonica OsPrx } 114(77)^{\mathrm{d}}\end{array}$ & $\begin{array}{l}\text { T. monococcum TmPRX3 }(96)^{\mathrm{g}} \\
\text { T. aestivum Pox } 2(96)^{\mathrm{e}} \\
\text { T. aestivum WP2 }(94)^{\mathrm{h}}\end{array}$ \\
\hline TaPrx112-M & EU595567 & 291 & 8.44 & $30,461.1$ & 23 & $\begin{array}{l}\text { H. vulgare peroxidase } 1 \text { precursor }(85)^{\mathrm{f}} \\
\text { O. sativa japonica OsPrx } 112(77)^{\mathrm{d}}\end{array}$ & $\begin{array}{l}\text { T. monococcum TmPRX3 }(100)^{\mathrm{g}} \\
\text { T. aestivum Pox } 2(99)^{\mathrm{e}} \\
\text { T. aestivum WP2 }(97)^{\mathrm{h}}\end{array}$ \\
\hline TaPrx113-A & EU595576 & 290 & 5.52 & $30,637.2$ & 22 & $\begin{array}{l}\text { H. vulgare subsp. vulgare } \\
\text { peroxidase }(93)^{\mathrm{i}} \\
\text { O. sativa japonica OsPrx } 114(78)^{\mathrm{d}}\end{array}$ & $\begin{array}{l}\text { T. monococcum TmPRX1 }(99)^{\mathrm{g}} \\
\text { T. aestivum } \operatorname{Pox} 3(96)^{\mathrm{e}} \\
\text { T. aestivum } \operatorname{TaPrx} 103(95)^{\mathrm{j}}\end{array}$ \\
\hline TaPrx113-B & EU595577 & 294 & 5.79 & $30,889.5$ & 22 & $\begin{array}{l}\text { H. vulgare peroxidase } 1 \text { precursor }(96)^{\mathrm{f}} \\
\text { O. sativa japonica OsPrx } 114(77)^{\mathrm{d}}\end{array}$ & T. monococcum TmPRX2 (99) \\
\hline TaPrx113-F & EU595578 & 294 & 5.79 & $30,932.5$ & 22 & $\begin{array}{l}\text { H. vulgare peroxidase } 1 \text { precursor }(96)^{\mathrm{f}} \\
\text { O. sativa japonica OsPrx114 }(77)^{\mathrm{d}}\end{array}$ & T. monococcum TmPRX2 (99) \\
\hline TaPrx114-A & EU595579 & 296 & 8.88 & $31,380.2$ & 23 & O. sativa japonica OsPrx $109(80)^{\mathrm{d}}$ & T. aestivum Pox4 (100) ${ }^{\mathrm{e}}$ \\
\hline $\operatorname{TaPrx} 114-B$ & EU595580 & 298 & 9.00 & $31,375.4$ & 23 & O. sativa japonica OsPrx109 (76) ${ }^{\mathrm{d}}$ & T. aestivum Pox4 (88) \\
\hline TaPrx114-C & EU595581 & 298 & 9.00 & $31,373.4$ & 23 & O. sativa japonica OsPrx109 (77) $)^{\mathrm{d}}$ & T. aestivum Pox4 $(85)^{\mathrm{e}}$ \\
\hline TaPrx108 & EU595582 & 293 & 6.09 & $31,106.8$ & 20 & O. sativa japonica OsPrx110 (77) ${ }^{\mathrm{d}}$ & $\begin{array}{l}\text { T. monococcum TmPRX5 }(99)^{\mathrm{g}} \\
\text { T. monococcum } \text { TmPRX4 }(98)^{\mathrm{g}}\end{array}$ \\
\hline TaPrx109-A & EU725463 & 304 & 6.08 & $33,458.0$ & 22 & O. sativa japonica OsPrx74 (85) ${ }^{\mathrm{d}}$ & ... \\
\hline TaPrx109-B1 to B5 & EU725464 to 68 & 304 & 6.26 & & 23 & O. sativa japonica OsPrx74 (84) ${ }^{\mathrm{d}}$ & $\ldots$ \\
\hline TaPrx109-C & EU725469 & 304 & 6.08 & $33,465.0$ & 25 & O. sativa japonica OsPrx74 (82) ${ }^{\mathrm{d}}$ & $\ldots$ \\
\hline
\end{tabular}

${ }^{a}$ Predicted mature protein characteristics and percent identity with closest GenBank proteins. Closest homologous protein, accession number, percent identity, and reference were obtained by BLAST at the National Center for Biotechnology Information server. PRX $=$ peroxidase.

${ }^{\mathrm{b}}$ Genomic sequences, except TaPrx109-C that corresponds to mRNA isolated from roots of H-93-8 line.

${ }^{\mathrm{c}}$ Amino acids number (AA); isoelectric point (pI) for mature protein was estimated by Swiss-Prot/TrEMBL.

${ }^{\mathrm{d}}$ Passardi et al. 2004.

${ }^{\mathrm{e}}$ Båga et al. 1995.

f Thordal-Christensen et al. 1992.

g Liu et al. 2005.

${ }^{\text {h }}$ Hertig et al. 1991.

${ }^{\mathrm{i}}$ Green 1991.

j Rebmann et al. 1991. 
zation of each peroxidase group transcripts during CCN infection. Sense and antisense probes spanning $3^{\prime}$ UTR of two transcripts (PRB-111-L and PRB-111-A) of group Taprx111, three (PRB-112-F, PRB-112-A, and PRB-112-Ab) of group Taprx112, and one (PRB-113-F) of group Taprxl13 were used (Fig. 5). The choice of probes (discussed below) in each group, three clones from Taprx112 and two from Taprx111, was done with the aim of unraveling different behaviors, if any, in the same group.

In resistant infected roots, each probe gave positive results by means of brown staining of cells injured by nematode migration. The most reactive sites were the cortical cells penetrated by the nematode and endodermal and pericycle cells injured by nematode feeding action. Surprisingly, syncytial cells did not give any reaction.

In particular, sections hybridized with the PRB-111-L probe showed a strong reaction just in cells delimiting nematode entrance (Fig. 6A) whereas, in the syncytium, no reaction was detected (Fig. 6B). In contrast, a very faint signal, only restricted to cells broken by the juvenile entrance and suggesting a wounding response, was observed in sections hybridized with PRB-111-A (Fig. 6C). In susceptible infected roots, PRB-111$\mathrm{L}$ and $\mathrm{PRB}-111-\mathrm{A}$ probes induced more or less the same reaction observed in the resistant line probed with PRB-111-A and previously suggested to be a wounding response (Fig. 6A', B', and C'). No signal was detected in the controls with both sense probes on resistant and susceptible wheat lines (Fig. 6D and D').

Sections of resistant H-93-8 hybridized with probes PRB112-F, PRB-112-A, and PRB-112-Ab showed the strongest signals. PRB-112-F probe gave heavy staining on cortical, endodermal, and vascular parenchyma cells directly injured by the nematode and appeared as amorphous stained aggregates (Fig. 6E). Cells of the same line challenged by nematode penetration strongly reacted also to probes PRB-112-A and PRB112-Ab (Fig. 6F and G). A ring of hyper-reacting cells entrap-
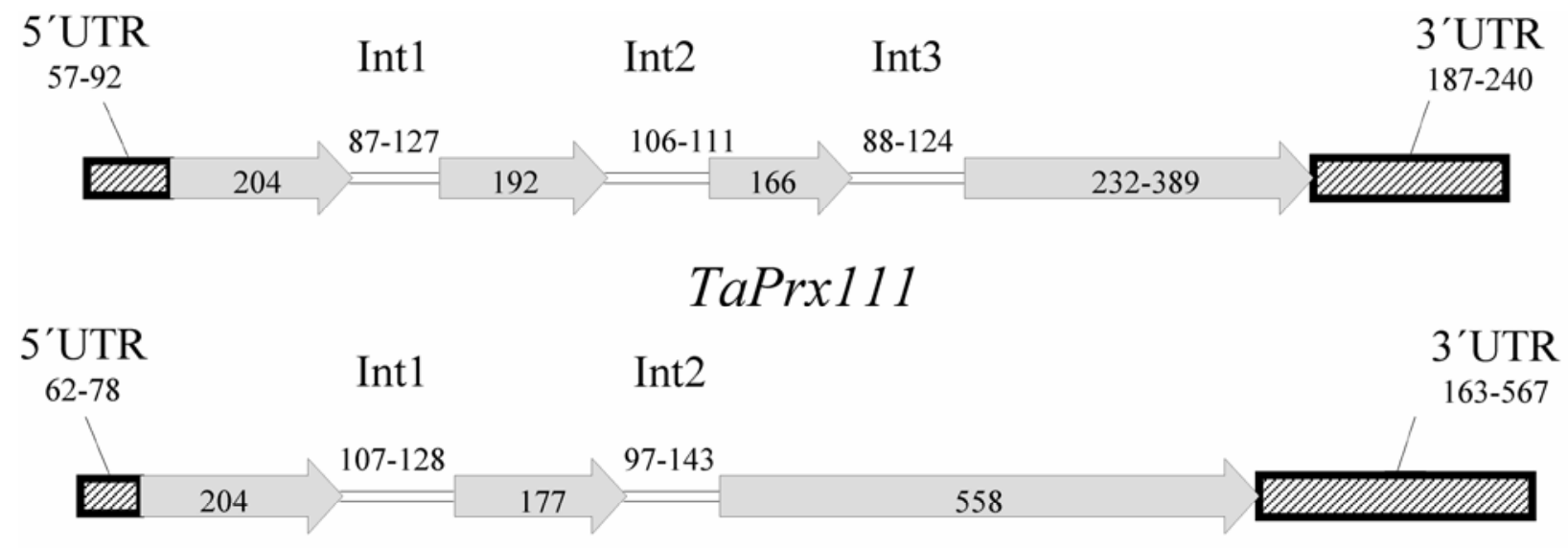

$\operatorname{TaPrx} 112$
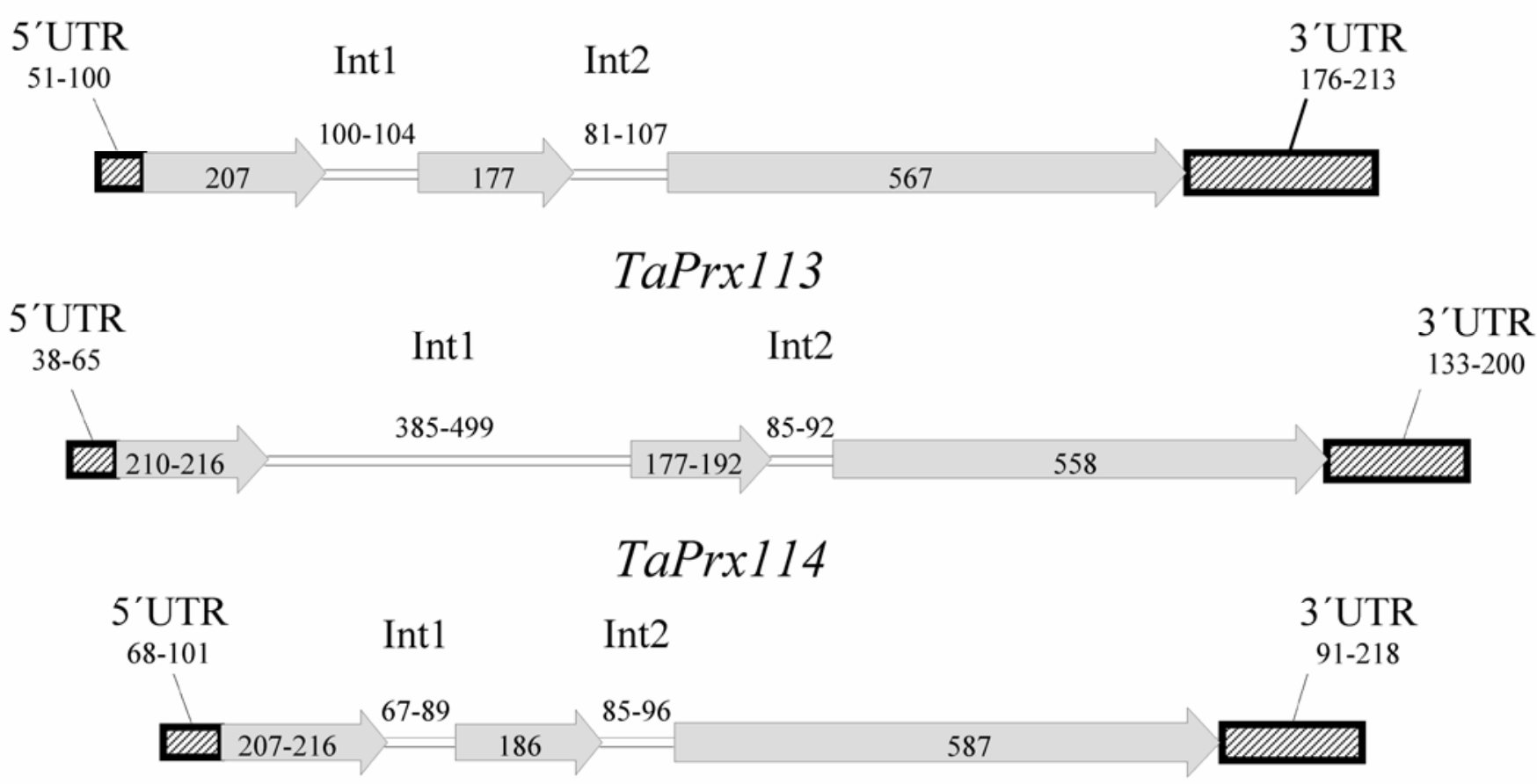

TaPrx 109

Fig. 2. Genomic organization of TaPrx gene groups. Coding regions (gray arrows), introns (double lines), untranslated regions (UTR) (striped boxes), and their sizes in terms of sequences (bp) are indicated. 
ping the nematodes at their feeding sites were observed in root sections probed with PRB-112-A (Fig. 6F). In contrast, a number of cortical cells affected by nematode penetration were labeled when probed with PRB-112-Ab (Fig. 6G). The PRB$112-\mathrm{F}$ probe showed heavy staining of collapsed cells bordering the endoderma in the susceptible root (Fig. 6E'), where reaction with probes PRB-112-A and PRB-112-Ab was poorly detectable (Fig. 6F' and G'). Each sense probe did not give a signal in either resistant or susceptible lines, as can be seen in Figure $6 \mathrm{H}$ and $\mathrm{H}^{\prime}$.

Probe PRB-113-F heavily labeled resistant cells injured by nematode invasion (Fig. 6I and J). All cortical cells challenged

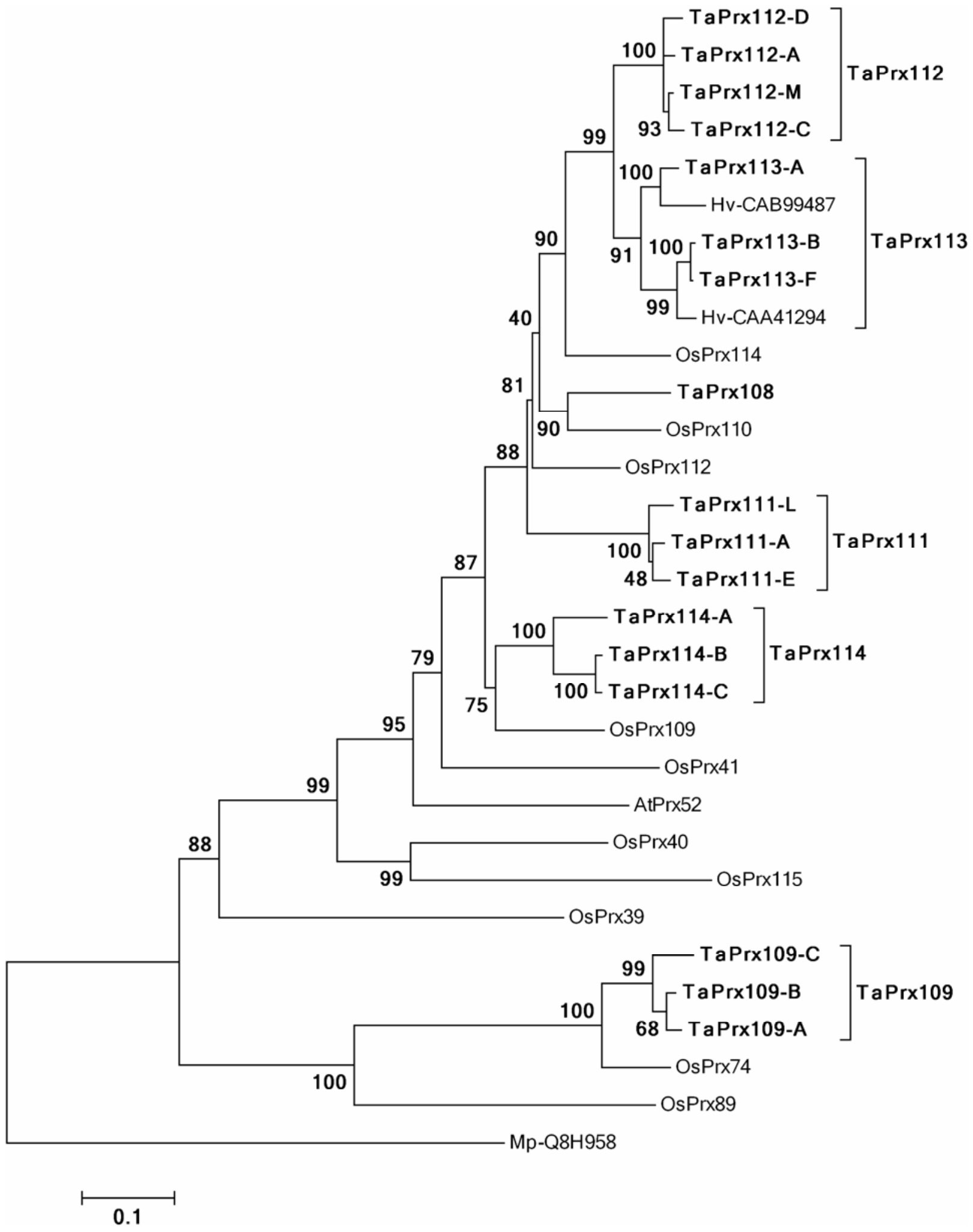

Fig. 3. Phylogenetic relationships based on predicted protein sequences from Triticum aestivum (TaPrx), representative rice (OsPrx) (Passardi et al. 2004), Arabidopsis (AtPrx52) (Tognolli et al. 2002), and Hordeum vulgare (Hv) (Green 1991; Thordal-Christensen et al. 1992) peroxidases. The tree was constructed by the neighbor-joining method and rooted with the peroxidase sequence of Marchantia polymorpha (Mp). Values at nodes indicate bootstrap supports. All branches are drawn to scale and bar represents 0.1 substitutions per site. 
by nematode penetration were strongly stained (Fig. 6I). Interestingly, parenchyma vascular cells selected by the nematode as its feeding site and developing into a syncytium showed great staining of the cytoplasm and partially digested walls (Fig. 6J). The same probe in the susceptible root induced a lighter reaction, where only the walls of cortical cells along the nematode entrance were brown stained (Fig. 6I' and J'). No signal at all was detected in the negative control (Fig. 6K and $\mathrm{K}^{\prime}$ ).
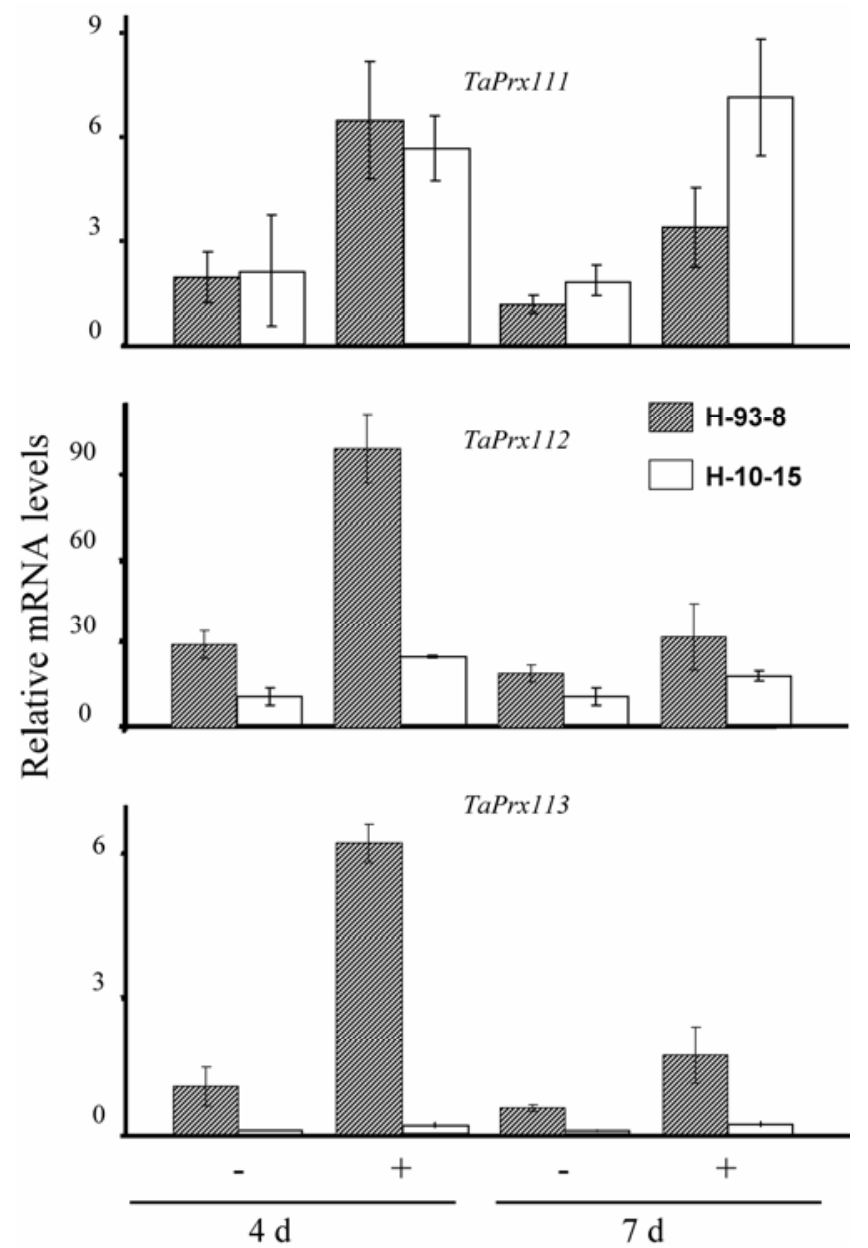

Fig. 4. Expression of TaPrx gene groups in wheat roots following Heterodera avenae infection. Steady-state mRNA levels of resistant $(\mathrm{H}-$ 93-8) and susceptible (H-10-15) wheat were normalized with respect to actin. All data are means \pm standard error of three replicates from four biological samples. Symbols: -, uninfected root; +, infected root at 4 and 7 days ( $4 \mathrm{~d}$ and $7 \mathrm{~d}$, respectively) after nematode inoculation.
Sections of uninfected roots of both resistant and susceptible genotypes did not show any signal no matter what probe was used (Fig. 6L and L').

\section{DISCUSSION}

Although several hypotheses have been formulated, the function of peroxidases in cereals has not been clearly assessed. The first aim of this study was to isolate and characterize the $P R X$ genes in wheat. Moreover, expression and localization of different genes to get more insights into their putative role, if any, in the defense response of wheat roots to $H$. avenae were investigated.

\section{Identification and characterization of root peroxidases.}

PRX are synthesized as preproteins with $\mathrm{N}$-terminal signal peptide and sometimes with $\mathrm{C}$-terminal extension which are removed to produce the mature protein (Buffard et al. 1990; Johansson et al. 1992; Welinder et al. 2002). Precursors are targeted either to the cell wall or vacuole, probably sorted by the $\mathrm{N}$ terminal and C terminal, respectively (Kristensen et al. 1999; Matsui et al. 2003). None of the PRX analyzed exhibited C-terminal extension, suggesting that they may be secreted to the apoplast and associated with ROS production as previously hypothesized for a group of $T$. monoccocum peroxidases (TmPRX1 to TMPRX6) by Liu and associates (2005). Alignment of deduced amino acid sequences from TaPrx genes revealed that they contain conserved structural features and activity sites of class III PRX such as the predicted $\mathrm{N}$-terminal signal peptide; the highly conserved $\mathrm{B}, \mathrm{D}$, and $\mathrm{F}$ domains essential to enzyme catalysis and protein folding (Welinder 1992); eight cysteine residues involved in the formation of four disulfide bridges; N-glycosylated triplets; and a variable region 40 to 50 amino acids toward the carboxyl end of the proximal hemebinding site (Fig. 1). It has been suggested that these variable sequences are correlated with the substrate specificity of the protein (Chittoor et al. 1999). The TaPrx 109 cluster was notably divergent because it possesses distinct amino acid sequences (Fig. 1) and structural features, which suggest a more ancient differentiation (Fig. 3). Furthermore, a 16-amino-acid domain, considered to be monocotyledon specific (Passardi et al. 2004), is only present in the TaPrx109 cluster (Fig. 1).

Sequences of the TaPrx109 group in the wheat genome were characterized for the first time in this study. All these genes showed high identity to rice peroxidase $0 s \operatorname{Pr} x 74$ at the DNA level (62 to $68 \%$ ), although they lacked the third intron characteristic of this gene. Additionally, this group exhibited the highest variability in its $3^{\prime}$ UTR, which may be related to alternative and regulated $3^{\prime}$ end processing. BLAST of TaPrx109 group sequences showed high identity to GenBank EST isolated from wheat plants under abiotic stress; however the bio-

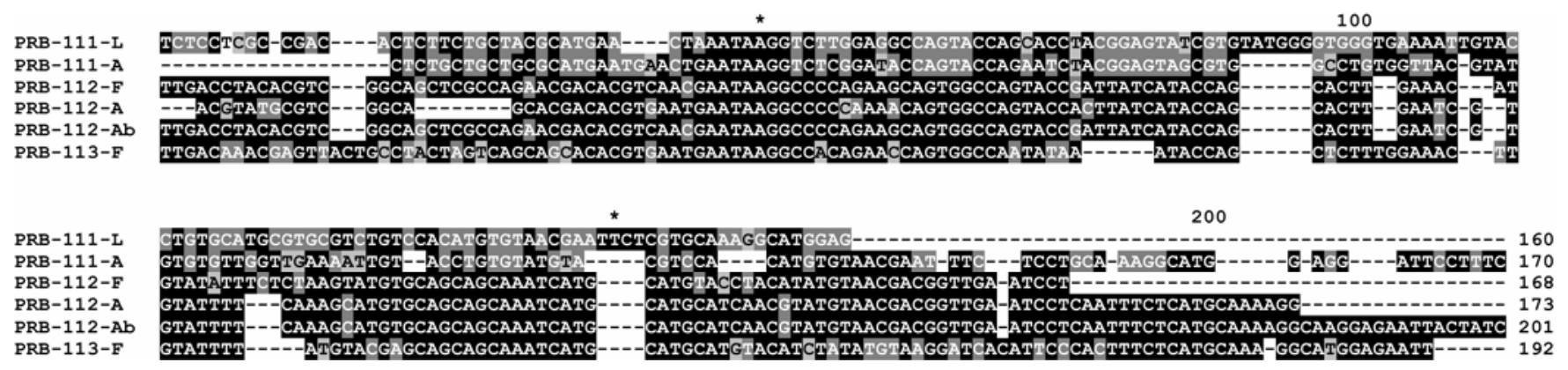

Fig. 5. Sequence alignment of gene-specific probes used for in situ hybridization. These sequences represent reverse-transcription polymerase chain reaction products spanning $3^{\prime}$ untranslated regions corresponding to TaPrx111 (PRB-111-L and PRB-111-A), TaPrx112 (PRB-112-F, PRB-112-A and PRB-112-Ab), and TaPrx113 (PRB-113-F) peroxidase groups. Gaps introduced for better alignment are shown by dashes. 
logical function of this group is still unknown. All 5'-RACE products isolated from the TaPrxl10 group gave truncated sequences lacking the $5^{\prime}$ region, indicating that they might be nonfunctional. Indeed, a complete wheat peroxidase sequence of this group has not been described to date, although a great number of sequences are available in the GenBank. The strongest homologous gene in rice, $\operatorname{OsP} \operatorname{Pr} 89$, was characterized by a very large third intron and detected at the mRNA level, despite containing retrovirus sequences (Passardi et al. 2004). DNA sequence alignment of the TaPrx groups showed more variants, mainly in introns and 5' and $3^{\prime}$ UTR regions, than those previously described for T. aestivum (Båga et al. 1995). It is possible that some of these variants originated from the three different ancestral wheat genotypes while others may have arisen from duplication or transposition events. The DNA sequences TaPrx113-A, pox3 (Båga et al. 1995), TmPRX1 (Liu et al. 2005), and pox381 (Rebmann et al. 1991) were also found to be very similar (identity of 93 to $98 \%$ ) (data not shown). All these genes were isolated from different wheat species, suggesting that they are variants of the same gene. Notable DNA sequence similarities were found between TaPrxl12-M, TmPRX3 (Liu et al. 2005), and pox2 (Båga et al. 1995) as well as between TaPrx111-E and poxl (Båga et al. 1995), which may also indicate a common origin. On the other hand, deduced protein sequences from TaPrx108, TaPrx111, TaPrx112, and TaPrx113 grouped with rice peroxidases OsPRX110, OsPRX112, and OsPRX114, whereas TaPrx114 fell into the same group with OsPRX109. All these rice PRX were assigned to group IV (Passardi et al. 2004), which contained peroxidases possibly involved in plant-pathogen interaction (Chittoor et al. 1997).

Most plant $P R X$ genes studied are found to be interrupted by two or three introns. TaPrx111 genes carry three introns as the characterized PRX genes of horseradish (Fujiyama et al. 1990) and Arabidopsis thaliana (Tognolli et al. 2002) within the Brassicaceae family. The three-intron model was found in wheat, rice, and Arabidopsis in a significant proportion and it could be the ancestral intron organization pattern. The other isolated PRX genes from wheat (TaPrx108 [not shown], TaPrx109, TaPrx112, TaPrx113, and TaPrxl14 groups) carried only two introns which are analogous to monocot $P R X$ (Båga et al. 1995; Passardi et al. 2004).

TaPrx111-H and TaPrx114-C genes were characterized by the presence of a very large intron containing nonautonomous transposons. It has been proposed that the rice introns could play a role as viral genomic insertion "buffers" protecting the plant against gene inactivation phenomena (Passardi et al. 2004). However, this defense system against insertions is, apparently, not always efficient (Casacuberta and Santiago 2003) because truncated proteins may be produced, as happens with the TaPrxl10 group (Fig. 1).

The presence of GC nucleotides in place of the invariant GT at the $5^{\prime}$ splice site of intron 1 in TaPrx111, TaPrx112, and TaPrx 114 seems not to affect the splicing process. Identical splice site patterns were also found in peroxidase genes of other plants (Mika et al. 2008; Xue and Rask 1995). GC-5' splice sites occur rarely and they were often found in genes coding for proteins involved in oxygen reactions (Jackson 1991a).

\section{Expression analyses of $P R X$ genes}

in wheat roots subjected to $H$. avenae infection.

Accumulation of TaPrx111, TaPrx112, and TaPrx113 peroxidase transcripts over their normal basal level was induced by nematode infection in both resistant and susceptible genotypes. In contrast, expression in TaPrx114 and TaPrx109 groups was not affected by nematode infection in both genotypes, suggesting that these two gene groups might not be directly involved in the defense response to $H$. avenae. Båga and associates (1995) reported that the expression level of the poxl gene, a peroxidase highly similar to TaPrx111, was not affected by powdery mildew infection. This may reflect changes in gene expression mediated by the two different ways of pathogen penetration, intracellularly in $\mathrm{CCN}$ and appressorium-mediated in Blumeria graminis, with and without wounding, respectively. This is supported by in situ hybridization results, in which TaPrxl11 peroxidase probes gave a brown staining just in cells delimiting nematode entrance, thus suggesting a wounding response. Indeed, all TaPrx111 sequences analyzed in this study carried a 10-bp inverted repeat located 17 bp upstream of the assigned TATA box (data not shown) that was previously proposed as a putative wound-induced regulatory sequence (Båga et al. 1995). In addition, the slightly higher accumulation of TaPrxl11 transcripts at 4 days in the resistant than in the susceptible line, but not at 7 days, suggests a putative role in the context of a general plant response, more related to wounding than to a specific reaction to nematode attack.

The highest expression level was detected for cluster TaPrxl12 independently of pathogen attack and genotype. These findings agree with previous results obtained for two similar wheat genes, poxwht and pox2, constitutively expressed in roots (Båga et al. 1995; Hertig et al. 1991) (Table 1). Moreover, the expression levels of clusters TaPrxl12 and TaPrxl13 were always much higher in the resistant H-93-8 line (3 and $10^{2}$-fold, respectively) (Fig. 4) than in the susceptible $\mathrm{H}-10-15$, and may be related to a constitutive mechanism of defense in the resistant wheat. The mode of action of some of these peroxidases would be similar to that described for TaPrx103 (previously named TaPERO) (Rebmann et al. 1991), which conferred enhanced resistance to $B$. graminis f. sp. tritici when it was constitutively or transiently expressed in transgenic wheat epidermis (Altpeter et al. 2005). Epidermal cells of transgenic lines were found to respond to B. graminis f. sp. tritici attack more frequently with hypersensitive cell death and generation of hydrogen peroxide (Schweizer 2008). Furthermore, a higher level of induction upon nematode infection was detected in $\mathrm{H}$ 93-8 wheat for TaPrxl12 and TaPrxl13 clusters. All in situ probes from these groups gave a strong reaction in cells injured by nematode migration in the resistant roots, suggesting that they may also be regulated by wounding. Possible regulatory G-box-like sequences were identified for pox 2 and pox 3 (Båga et al. 1995) and these seem to be required for woundinduced expression (Kawaoka et al. 1994). Whether any of these regulatory sequences is involved in gene regulation during nematode-plant interactions remains to be elucidated. Interestingly, infected roots from resistant wheat lines showed a heavy reaction in cells close to the vascular cylinder and parenchyma vascular cells when probed with PRB-112-F and PRB-113-F. These peroxidases could, then, play a role in the early resistance response by leading to membrane degradation and related death of cells selected as feeding sites and affected by nematode oesophageal secretions. This seems to be confirmed by the accumulation of the PBR-113-F probe signal just in the cells where the nematode, starting its feeding, is inducing the syncytial development. The stronger signal in the resistant than in the susceptible line, totally in agreement with qRT-PCR results, might suggest an early and heavy response of resistant cells to signals triggered by glandular nematode secretions. Our data also provide evidence that each TaPrx group responds in a different way to signals from the nematode and, as a whole, cooperate to limit root disease.

Evaluating the function of each peroxidase isoform is quite difficult because of the redundancy of $P R X$ genes in plants (Cosio and Dunand 2009). Therefore, it would be necessary to carry out further studies, such as the generation of transgenic 

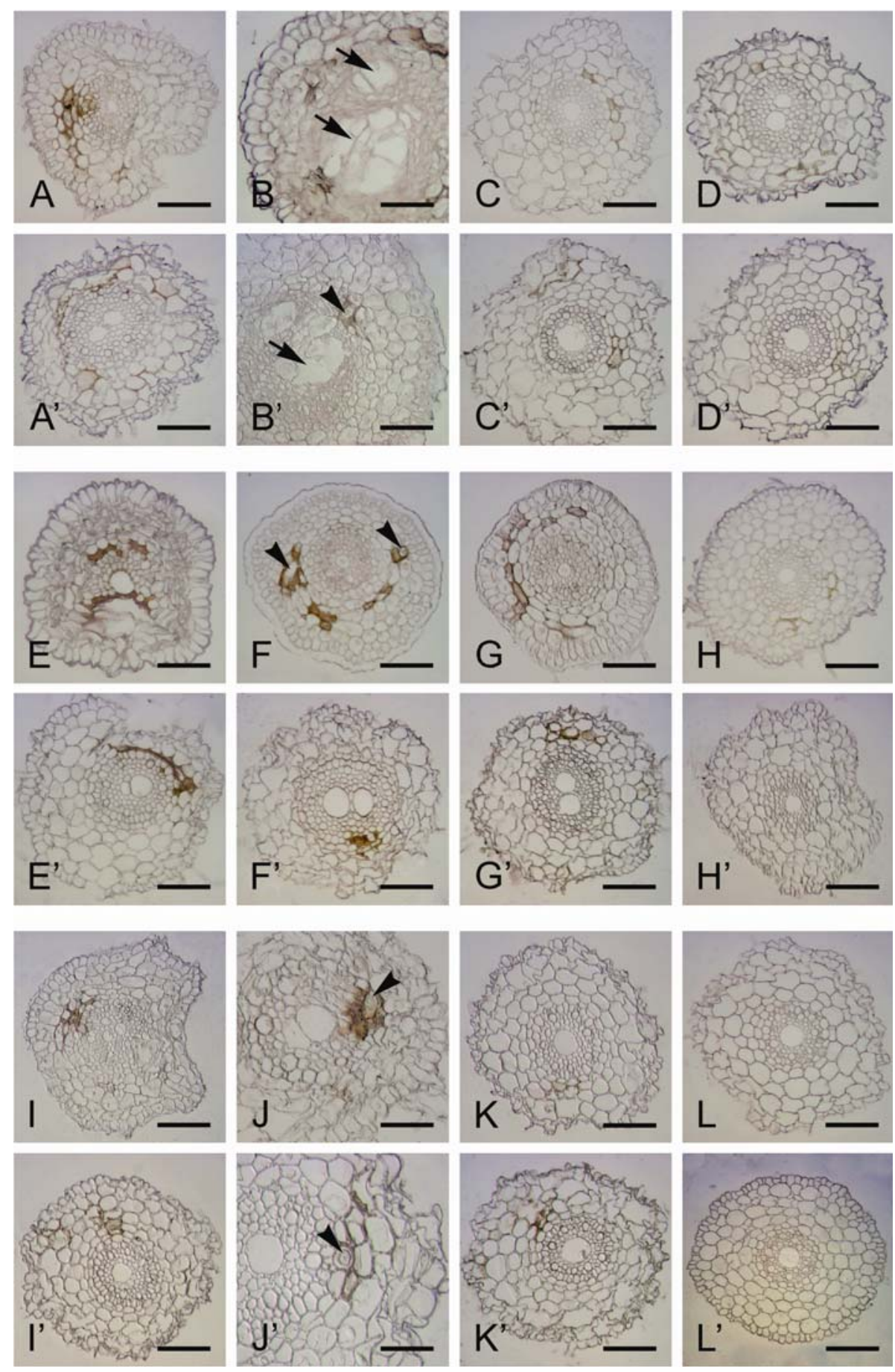

Fig. 6. In situ localization of peroxidase (Prx) transcripts in 4-day nematode-infected and uninfected H-93-8 (resistant) and H-10-15 (susceptible) wheat root sections. Cross sections of A through D, resistant and A' through D', susceptible roots hybridized to digoxigenin (DIG)-labeled Taprx111 group probes. A, B and A', B', PRB-111-L and C, C', PRB-111-A antisense probes; and D, D', control sense probe. A, PRB-111-L revealed a number of cortical and parenchyma vessel cells of H-93-8 roots strongly reacting to nematode penetration and its feeding action. B, Detail of root reacted cells and unlabeled syncytia (arrows). A', In contrast, few cortical and parenchyma vessel cells in H-10-15 roots showed a light brown staining as a consequence of nematode penetration and its feeding action. B', Nematode (arrowhead) in reacting parenchyma cells and completely unaffected syncytia (arrow). C, C', Very faint signal, only in the cells broken by nematode entrance, is detectable in resistant and susceptible roots probed with PRB-111-A. D, D', Negative controls were completely unstained. Cross sections of $\mathbf{E}$ through H, resistant and E' through H', susceptible roots hybridized to DIG-labeled Taprx112 group probes. E, E', PRB-112-F, F, F', PRB-112-A, and G, G', PRB-112$\mathrm{Ab}$ antisense probes; and $\mathbf{H}, \mathbf{H}$, control sense probe. E, PRB-112-F probe gave the strongest signal in cortical, endodermal, and vascular parenchyma cells of $\mathrm{H}-$ 93-8 as well as in E', cortical cells bordering the endoderma in H-10-15. F, Resistant root probed with PRB-112-A showed a ring of hyper-reacting cells entrapping the nematode (arrowhead) at its feeding site while F', susceptible root appeared to be less sensitive to the probe and showed reaction in very few parenchyma cells. G, PRB-112-Ab, which gave a strong labeling in cortical cells of H-93-8 endangered by nematode penetration, did not greatly affect G', susceptible root tissues. H, H', Sense probe did not give any staining in both resistant and susceptible root cells. Cross sections of I-K, resistant and I' through K', susceptible roots hybridized to DIG-labeled PRB-113-F probes. I, J and I', J', PRB-113-F antisense probe and K, K', control sense probe. I, Probe induced heavy reaction in cells of H-93-8 affected by nematode invasion and, in particular, in parenchyma vascular cells selected as nematode (arrowhead) feeding site where $\mathbf{J}$, a developing syncytium showed strong staining of its cytoplasm and cell walls. I', J', PRB-113-F only labeled the walls of cortical cells at nematode (arrowhead) entrance but not cells of vascular cylinder in H-10-15. K, K', No signal at all was detectable in the negative controls. View of $\mathbf{L}$, resistant and $\mathbf{L}$, susceptible uninfected root sections which were not reactive to each probe used. Scale bar: B, B' and J, J' $=1.8 \mu \mathrm{m}$; all others $=2.8 \mu \mathrm{m}$. 
plants overexpressing (Schweizer 2008) or silencing (Bindschedler et al. 2006) different peroxidase genes, in order to analyze their specific involvement in plant resistance.

\section{MATERIALS AND METHODS}

Plant material and nematodes.

The experiments were performed on wheat line H-93-8, carrier of the $\mathrm{Cre} 2 \mathrm{CCN}$ resistance gene derived from the cross ( $T$. turgidum subsp. turgidum cv. Rubroatrum, H-1-1 $\times$ Aegilops ventricosa AP-1) $\times$ T. aestivum cv. Almatense, H-10-15 (previously described) (Delibes et al. 1993; Mena et al. 1993); its parents, T. aestivum $\mathrm{H}-10-15$ and T. turgidum $\mathrm{H}-1-1$, both without CCN resistance genes; and $A$. ventricosa AP-1. Hereafter, abbreviations H-93-8, H-10-15, H-1-1, and AP-1 will be used.

The CCN $(H$. avenae) population from a naturally infested plot at the La Poveda Experimental Station in Arganda (Madrid) had previously been characterized as belonging to the Ha71 pathotype (López-Braña et al. 1996; Romero et al. 1996). Seed of the resistant H-93-8 and susceptible H-10-15 wheat lines were germinated on wet paper after surface sterilization with $5 \%$ sodium hypochlorite and sowed in 5 -cm-diameter plates containing $10 \mathrm{ml}$ of wet sterilized sand and maintained at $15 \pm 2{ }^{\circ} \mathrm{C}$ in a growth chamber. At $48 \mathrm{~h}$, seedlings were divided in two groups: one was inoculated with 100 J2s of the Ha71 $H$. avenae pathotype per plant and the second one (uninfected seedlings) was used as a control as described by Andrés and associates (2001). Roots and leaves of infected plants were harvested 4 and 7 days after inoculation, as well as uninoculated tissues utilized as the control. Root and leaf strips were flash frozen in liquid nitrogen and then stored at $-80^{\circ} \mathrm{C}$ until further use.

\section{RNA purification and RT-PCR analysis.}

Total RNA was isolated according to Båga and associates (1995). Concentration of each RNA sample was measured using a NanoDrop ND-1000 spectrophotometer (Thermo Fisher Scientific Inc., Waltham, MA, U.S.A.). Only the RNA samples with a 260/280 ratio between 1.9 and 2.1 and 260/230 ratio greater than 2.0 were used. Validation of RNA quality was performed by using the RNA 6000 Nano Assay on an Agilent 2100 Bioanalyzer (Agilent Technologies, Palo Alto, CA, U.S.A.).

$P R X$ cDNA syntheses were performed using the Superscript one-step RT-PCR kit for 3' RACE (Invitrogen Life Technologies, San Diego, CA, U.S.A.) and the SMART RACE cDNA Amplification Kit for 5' RACE (Takara Bio Company, Mountain View, CA, U.S.A.) in accordance with the manufacturers' recommendations. The primers used for amplification are shown in Supplementary Tables 1 and 2. RACE reactions were

Table 2. Primer sequences used in quantitative real-time polymerase chain reaction analysis

\begin{tabular}{llc}
\hline $\begin{array}{l}\text { Peroxidase } \\
\text { cluster }\end{array}$ & \multicolumn{1}{c}{ Primer pair sequences } & $\begin{array}{c}\text { Size } \\
(\mathbf{b p})^{\mathbf{a}}\end{array}$ \\
\hline TaPrx111 & GACTGCTTCGTCGATGGATGT & $\ldots$ \\
& TGCCTCGAATGGAATTGTTG & 103 \\
TaPrx113 & ATTGACAAACGAGTTACTGCCTACTAG & $\ldots$ \\
& GATTTGCTGCTGCTCGTACA & 126 \\
TaPrx112 & CGGTGACACCAACATCAACACTG & $\ldots$ \\
& CAGGAGCCCTTTCTGTGACAG & 146 \\
TaPrx114 & CAGTGCCGGTTTTTCAGGAG & $\ldots$ \\
& TATGCGTTGTCGAACCCGTT & 158 \\
TaPrx109 & TCTCCGACCGGCTCTACAACTT & $\ldots$ \\
Actin & GCTGGCACACTTGCTCTTTAGC & 104 \\
& GAAGCTGCAGGTATCCATGAGACC & $\ldots$ \\
& AGGCAGTGATCTCCTTGCTCATC & 151 \\
\hline
\end{tabular}

${ }^{\text {a }}$ Expected amplicon size. carried out in a Mastercycler Gradient (Eppendorf HQ, Hamburg, Germany) with $0.5 \mathrm{U}$ of AmpliTaq Gold (Applied Biosystems, Foster City, CA, U.S.), $150 \mathrm{ng}$ of DNA, and $250 \mathrm{nM}$ each primer in a 20 - $\mu$ l volume, with $10 \mathrm{~min}$ of initial denaturation at $94^{\circ} \mathrm{C}$. Different combinations of annealing temperatures and extension times were tested to find the optimal conditions for each primer pair. PCR products were fractionated on a 1 to $2 \%$ agarose gel using Tris-acetate-EDTA buffer and stained with ethidium bromide. DNA bands were eluted with a QIAEX II gel extraction kit (Qiagen Inc., Valencia, CA, U.S.A.) and products were cloned in the pGEM-T Easy vector system (Promega Biotech Ibérica, SL, Alcobendas, Madrid,) following manufacturer's indications.

\section{DNA extraction, amplification, and cloning.}

Total genomic DNA was extracted according to the cetyltrimethylammonium bromide procedure described by Taylor and Powell (1982). Preferential amplification of sequences from individual $P R X$ genes was obtained with primers shown in Supplementary Table 3 . PCR products were treated as previously described for RT-PCR.

\section{Real-time PCR analysis.}

First-strand cDNA was synthesized by reverse transcribing 2 $\mu \mathrm{g}$ of total RNA in a final reaction volume of $20 \mu \mathrm{l}$ using a High-Capacity cDNA Reverse Transcription kit (Applied Biosystems) following the manufacturer's instructions. Primers specific for each PRX group were designed from 3' lowhomology regions using Primer Express 2.0 software (Applied Biosystems). The primer sequences are shown in Table 2. The PCR mixture contained $1 \mu$ l of fivefold diluted cDNA, $10 \mu \mathrm{l}$ of Power SYBR Green PCR Master Mix (Applied Biosystems), and $300 \mathrm{nM}$ each gene-specific primer in a final volume of $20 \mu \mathrm{l}$. PCR without template were also performed for each primer pair as controls. Data acquisitions were carried out with an ABI Prism 7300 Sequence Detection System and software (Applied Biosystems). Cycling conditions for all reactions were $10 \mathrm{~min}$ at $95^{\circ} \mathrm{C}$ (denaturation), 40 cycles of $15 \mathrm{~s}$ at $95^{\circ} \mathrm{C}$, and $1 \mathrm{~min}$ at 60 to $68^{\circ} \mathrm{C}$ in 96 -well optical reaction plates (Applied Biosystems). The specificity of amplicons was verified by melting curve analysis $\left(60\right.$ to $95^{\circ} \mathrm{C}$ ) after 40 cycles and agarose gel electrophoresis. All genes were analyzed in triplicate from four independently isolated RNA samples. The cycle threshold $\left(C_{t}\right)$ values were normalized to a conventional reference gene (actin) using the primer pairs showed in Table 2. Two different approaches were used to process qRT-PCR data: i) the relative quantification method which assumes that amplification efficiencies are equal to 2 and equal between all reactions (Pfaffl 2001) and ii) the method based on the kinetics of individual PCR reactions. In the latter case, raw fluorescence values, as a function of cycles, were exported into the realtime PCR Miner program (Zhao and Fernald 2005) to calculate the efficiency and $C_{t}$ values for individual PCR reactions.

\section{DNA sequencing and data analysis.}

Sequencing was done on an Applied Biosystem ABIPRISM 3100 sequencer (Applied Biosystems). PRX homology sequences were searched with BLAST via the National Center for Biotechnology Information web server (Altschul et al. 1997). Amplified fragments were aligned to obtain full-length cDNA and genomic-DNA PRX sequences. We adopted the nomenclature used in rice (Passardi et al. 2004), with the letters "Ta" for T. aestivum and "Prx" for peroxidase, followed by a number, corresponding to clusters, and a letter, indicating variants inside each cluster. The splicing sites of introns were identified by the alignment of genomic DNA to EST or cDNA sequences. Transposable elements in genomic DNA introns 
were searched by comparison with Repbase through the Genetic Information Research Institute server (Kohany et al. 2006). The corresponding coding sequences were translated with the "translate" tool on the ExPASy Proteomics Server and controlled for specific peroxidase motifs. All DNA and protein sequence alignments were performed via the Plateforme Bioinformatique de la Genépole server with Multalin (Corpet 1988) and visually adjusted with the GeneDoc program (Nicholas et al. 1997). The N-terminal signal peptides of deduced amino acid sequences were predicted with the SIGNALP 3.0 server (Bendtsen et al. 2004). The distance tree was constructed with the NEIGHBOR option under the JTT substitution frequency matrix, and 1,000 bootstrap replicates were carried out for this method with MEGA software version 3.1 (Tamura et al. 2007).

\section{In situ hybridization.}

Four-day nematode-infected and -uninfected roots from $\mathrm{H}$ 93-8 and H-10-15 wheat lines were fixed in 4\% formaldehyde in phosphate-buffered saline (PBS) and embedded in paraffin wax as described by Jackson (1991b) with some modifications. To discriminate the three groups of peroxidases TaPrx111, TaPrx112, and TaPrx113 (with a high conservation of sequences in the coding region), the nucleotide sequences corresponding to the $3^{\prime}$ UTR were aligned. The selection of the probe was done, taking into account the sequence which was more representative, in terms of percentage of similarity of i) the entire group (PRB-113-F), ii) some intragroup clusters (PRB-112-F, PRB-112-A, PRB-112-Ab, and PRB-111-A), and iii) the uniqueness of a single member of the group (PRB-111-L). The specific cDNA fragments spanning 3' UTR were obtained by RT-PCR (Fig. 5). The peroxidase cDNAs were then cloned into pGEM-T Easy vector. Sense and antisense digoxygeninlabeled riboprobes were produced by in vitro transcription of linearized plasmid DNA using T7 and SP6 RNA Polymerase (Roche Diagnostic, Mannheim, Germany), respectively, according to the manufacturer's instructions. Hybridization of the samples was performed at $54^{\circ} \mathrm{C}$ overnight with $50 \mathrm{ng}$ of riboprobe. Afterward, the slides were soaked twice in prewarmed $\left(54^{\circ} \mathrm{C}\right) 0.2 \times \mathrm{SSC}(1 \times \mathrm{SSC}$ is $0.15 \mathrm{M} \mathrm{NaCl}$ plus 0.015 $M$ sodium citrate) for $30 \mathrm{~min}$, rinsed twice for $5 \mathrm{~min}$ with NTE solution $(500 \mathrm{mM} \mathrm{NaCl} ; 10 \mathrm{mM}$ Tris- $\mathrm{HCl}, \mathrm{pH} 8$; and $1 \mathrm{mM}$ EDTA) at $37^{\circ} \mathrm{C}$, and incubated for $30 \mathrm{~min}$ at $37^{\circ} \mathrm{C}$ in a prewarmed NTE solution containing RNase A at $20 \mu \mathrm{g} / \mathrm{ml}$. Slides were then rinsed for $5 \mathrm{~min}$ in NTE solution at $37^{\circ} \mathrm{C}$ twice and washed for $1 \mathrm{~h}$ in $0.2 \times \mathrm{SSC}$ at $54^{\circ} \mathrm{C}$ and $5 \mathrm{~min}$ in $\mathrm{PBS}$ at room temperature. The hybridized probes were detected using an alkaline phosphatase-conjugated antibody $(1: 1,000)$. The color reaction, obtained by using NBT-BCIP (Roche Diagnostic) as substrate, was stopped by adding Tris-EDTA. Sections were mounted in Aquatext (Merck, Darmstadt, Germany) on glass slides and viewed under a bright-field microscope.

\section{ACKNOWLEDGMENTS}

We thank C. Gónzalez-Belinchón, R. Lerario, M. López-Sanz, and R. Rodríguez-Rios for their technical assistance; and T. Bleve for their critical reading of the manuscript. This work was supported by grant AGL200406791-C04-01 from the Ministerio de Ciencia y Tecnología of Spain and benefited from interactions funded through COST Action 872.

\section{LITERATURE CITED}

Altpeter, F., Varshney, A., Abderhalden, O., Douchkov, D., Sautter, C., Kumlehn, J., Dudler, R., and Schweizer, P. 2005. Stable expression of a defense-related gene in wheat epidermis under transcriptional control of a novel promoter confers pathogen resistance. Plant Mol. Biol. 57:271283.
Altschul, S. F., Madden, T. L., Schaffer, A., Zhang, J., Zhang, Z., Miller, W., and Lipman, D. J. 1997. Gapped blast and psiblast, a new generation of protein database search programs. Nucleic Acids Res. 25:33893402 .

Andrés, M. F., Melillo, M. T., Delibes, A., Romero, M. D., and BleveZacheo, T. 2001. Changes in wheat roots enzymes correlated with resistance to cereal cyst nematode. New Phytol. 152:343-354.

Båga, M., Chibbar, R. N., and Kartha, K. K. 1995. Molecular cloning and expression analysis of peroxidase genes from wheat. Plant Mol. Biol. 29:647-662.

Bendtsen, J. D., Nielsen, H., von Heijne, G., and Brunak, S. 2004. Improved prediction of signal peptides: SignalP 3.0. J. Mol. Biol. 340:783-795.

Bindschedler, L. V., Dewdney, J., Blee, K. A., Stone, J. M., Asai, T., Plotnikov, J., Denoux, C., Hayes, T., Gerrish, C., Davies, D. R., Ausubel, F. M., and Bolwell, G. P. 2006. Peroxidase-dependent apoplastic oxidative burst in Arabidopsis required for pathogen resistance. Plant J. 47:851-863.

Bolwell, G. P., Bindschedler, L. V., Blee, K. A., Butt, V. S., Davies, D. R., Gardner, S. L., Gerrish, C., and Minibayeva, F. 2002. The apoplastic oxidative burst in response to biotic stress in plants: a three component system. J. Exp. Bot. 53:1367-1376.

Buffard, D., Breda, C., van Huystee, R. B., Asemota, O., Pierre, M., Ha, D. B. D., and Esnault, R. 1990. Molecular cloning of complementary DNAs encoding two cationic peroxidases from cultivated peanut cells. Proc. Natl. Acad. Sci. U.S.A. 87:8874-8878.

Casacuberta, J. M., and Santiago, N. 2003. Plant LTR-retrotransposons and MITEs: control of transposition and impact on the evolution of plant genes and genomes. Gene 311:1-11.

Chittoor, J. M., Leach, J. E., and White, F. F. 1997. Differential induction of a peroxidase gene family during infection of rice by Xanthomonas oryzae pv. oryzae. Mol. Plant-Microbe Interact. 10:861-871.

Chittoor, J. M., Leach, J. E., and White, F. F. 1999. Induction of peroxidase during defense against pathogens. Page 171-193 in: PathogenesisRelated Proteins in Plants. S. K. Datta and S. Muthukrishnan, eds. CRC Press, Boca Raton, FL, U.S.A.

Corpet, F. 1988. Multiple sequence alignment with hierarchical clustering. Nucleic Acids Res. 16:10881-10890.

Cosio, C., and Dunand, C. 2009. Specific functions of individual class III peroxidase genes. J. Exp. Bot. 60:391-408.

Cosio, C., Vuillemin, L., De Meyer, M., Kevers, C., Penel, C., and Dunand, C. 2009. An anionic class III peroxidase from zucchini may regulate hypocotyl elongation through auxin oxidase activity. Planta 229:823836.

Das, S., DeMason, D. A., Ehlers J. D., Close, T. J., and Roberts, P. A. 2008. Histological characterization of root-knot nematode resistance in cowpea and its relation to reactive oxygen species modulation. J. Exp. Bot. 59:1305-1313.

Delibes, A., Romero, M. D., Aguaded, S., Duce, A., Mena, M., LópezBraña, I., Andrés, M. F., Martín-Sánchez, J. A., and García-Olmedo, F. 1993. Resistance to the cereal cyst nematode (Heterodera avenae) transferred from the wild grass Aegilops ventricosa to hexaploid wheat by a "stepping stone" procedure. Theor. Appl. Genet. 87:402-408.

Eastwood, R. F., Lagudah, E. S., and Appels, R. 1994. A directed search for DNA sequences tightly linked to cereal cyst nematode resistance genes in Triticum tauschii. Genome 37:311-319.

Fujiyama, K., Takemura, H., Shinmyo, A., Okada, H., and Takano, M. 1990. Genomic DNA structure of two new horseradish-peroxidaseencoding genes. Gene 89:163-169.

Golinowski, W., Grundler, F. M. W., and Sobczak, M. 1996. Changes in the structure of Arabidopsis thaliana during female development of the plant parasitic nematode Heterodera schachtii. Protoplasma 194:103116.

Green, R. M. 1991. Isolation and characterisation of genes induced in barley during powdery mildew infection. Ph.D. thesis, University of Cambridge, U.K.

Hertig, C., Rebmann, G., Bull, J., Mauch, F., and Dudler, R. 1991. Sequence and tissue-specific expression of a putative peroxidase gene from wheat (Triticum aestivum L.). Plant Mol. Biol. 16:171-174.

Hirada, S., Sasaki, K., Ito, H., Ohashi, Y., and Matsui, H. 2001. A large family of class III plant peroxidases. Plant Cell Physiol. 42:462-468.

Jackson, I. J. 1991a. A reappraisal of non-consensus mRNA splice sites. Nucleic Acids Res. 19:3795-3798.

Jackson, D. P. 1991b. In situ hybridization in plants. Pages 157-181 in: Molecular Plant Pathology: A Practical Approach. D. J. Bowles, S. J. Gurr, M. McPherson, eds. Oxford University Press, Oxford.

Johansson, A., Rasmussen, S. K., Harthill, J. E., and Welinder, K. G. 1992. cDNA, amino acid and carbohydrate sequence of barley seed-specific peroxidase BP1. Plant Mol. Biol. 18:1151-1161.

Kawano, T. 2003. Roles of the reactive oxygen species-generating peroxi- 
dase reactions in plant defense and growth induction. Plant Cell Rep. 21:829-837.

Kawaoka, A., Kawamoto, T., Sekine, M., Yoshida, K., Takano, M., and Shinmyo, A. 1994. A cis-acting element and a transacting factor involved in the wound-induced expression of a horseradish peroxidase gene. Plant J. 6:87-97.

Kohany, O., Gentles, A. J., Hankus, L., and Jurka, J. 2006. Annotation, submission and screening of repetitive elements in Repbase: RepbaseSubmitter and Censor. BMC Bioinformatics 7:474-481.

Kristensen, B. K., Bloch, H., and Rasmussen, S. K. 1999. Barley coleoptile peroxidases. Purification molecular cloning and induction by pathogens. Plant Physiol. 120:501-512

Liu, G., Sheng, X., Greenshields, D. L., Ogieglo, A., Kaminskyj, S., Selvaraj, G., and Wei, Y. 2005. Profiling of wheat class III peroxidase genes derived from powdery mildew-attacked epidermis reveals distinct sequence-associated expression patterns. Mol. Plant-Microbe Interact. 18:730-741

López-Braña, I., Romero, M. D., and Delibes, A. 1996. Application of the random amplified polymorphic DNA (RAPD) technique for analysis of Heterodera avenae complex populations. Genome 39:118-122.

Matsui, T., Nakayama, H., Yoshida, K., and Shinmyo, A. 2003. Vesicular transport route of horseradish Cla peroxidase is regulated by $\mathrm{N}$ - and Cterminal pro-peptides in tobacco cells. Appl. Microbiol. Biotechnol. 62:517-522

Melillo, M. T., Leonetti, P., Bongiovanni, M., Castagnone-Sereno, P., and Bleve-Zacheo, T. 2006. Modulation of reactive oxygen species activities and $\mathrm{H}_{2} \mathrm{O}_{2}$ accumulation during compatible and incompatible tomato-root-knot nematode interactions. New Phytol. 170:501-512.

Mellersh D. G., Foulds I. V., Higgins V. J., and Heath M. 2002. $\mathrm{H}_{2} \mathrm{O}_{2}$ plays different roles in determining penetration failure in three diverse plantfungal interactions. Plant J. 29:257-268.

Mena, M., Orellana, J., Lopez-Braña, I., García-Olmedo, F., and Delibes, A. 1993. Characterization of wheat/Aegilops ventricosa introgression and addition lines with respect to the $\mathbf{M}^{\mathrm{v}}$ genome. Theor. Appl. Genet. 86:197-204.

Mika, A., Buck, F., and Lüthje, S. 2008. Membrane-bound class III peroxidases: Identification, biochemical properties and sequence analysis of isoenzymes purified from maize (Zea mays L.) roots. J. Proteomics 71:412-424

Montes, M. J., López-Braña, I., Romero, M. D., Sin, E., Andrés, M. F., Martín-Sánchez, J. A., and Delibes, A. 2003. Biochemical and genetic studies of two Heterodera avenae resistance genes transferred from Aegilops ventricosa to wheat. Theor. Appl. Genet. 107:611-618.

Montes, M. J., López-Braña, I., and Delibes, A. 2004. Root enzyme activities associated with resistance to Heterodera avenae conferred by gene $\mathrm{Cre} 7$ in a wheat/Aegilops triuncialis introgression line. J. Plant Physiol. 161:1135-1140.

Montes, M. J., Andrés, M. F., Sin, E., López-Braña, I., Martín-Sánchez, J. A., Romero, M. D., and Delibes, A. 2008. Cereal cyst nematode resistance conferred by the Cre 7 gene from Aegilops triuncialis and its relationship with Cre genes from Australian wheat cultivars. Genome 51:315-319.

Nicholas, K. B., Nicholas, H. B., Jr., and Deerfield, D. W., II. 1997 GeneDoc: analysis and visualization of genetic variation. EMBNEW.news 4:14-17

Nicol, J. M., and Rivoal, R. 2007. Global knowledge and its application for the integrated control and management of nematodes on wheat. Pages 243-287 in: Integrated Management and Biocontrol of Vegetable and Grain Crops Nematodes. A. Ciancio and K. G. Mukerji, eds. Springer, The Netherlands.

Nürnberger, T., Brunner, F., Kemmerling, B., and Piater, L. 2004. Innate immunity in plants and animals: striking similarities and obvious differences. Immunol. Rev. 198:249-266.

Ogbonnaya, S., Seah, I., Delibes, A., Jahier, J., Lopez-Braña, I., Eastwood, R. F., and Lagudah, E. S. 2001. Molecular-genetic characterisation of nematode resistance from Aegilops ventricosa and its derivatives in wheat. Theor. Appl. Genet. 102:623-629.

Østergaard, L., Teilum, K., Mirza, O., Mattsson, O., Petersen, M., Welinder, K.G., Mundy, J., Gajhede, M., and Henriksen, A. 2000. Arabidopsis ATP A2 peroxidase. Expression and high-resolution structure of a plant peroxidase with implications for lignification. Plant Mol. Biol. 44:231-243.

Passardi, F., Longet, D., Penel , C., and Dunand, C. 2004. The class III peroxidase multigenic family in rice and its evolution in land plants. Phytochemistry 65:1879-1893.

Passardi, F., Cosio, C., Penel, C., and Dunand, C. 2005. Peroxidases have more functions than a Swiss army knife. Plant Cell Rep. 24:255-265.

Pfaffl, M. W. 2001. A new mathematical model for relative quantification in real-time RT-PCR. Nucleic Acids Res. 29:e45.

Rebmann, G., Hertig, C., Bull, J., Mauch, F., and Dudler, R. 1991. Cloning and sequencing of cDNAs encoding a pathogen-induced putative peroxidase of wheat (Triticum aestivum L.). Plant Mol. Biol. 16:329-331.

Rivoal, R., Bekal, S., Valette, S., Gauthier, P., Bel Hadj Fradj, M., Mokabli, A., Jahier, J., Nicol, J., and Yahyaoui, A. 2001. Variation in reproductive capacity and virulence on different genotypes and resistance genes of Triticeae, in the cereal cyst nematode species complex. Nematology 3:581-592.

Romero, M. D., Andrés, M. F., Lopez-Braña, I., and Delibes, A. 1996. Pathogenic and biochemical comparison of two Spanish populations of Heterodera avenae. Nematol. Mediterr. 24:235-244.

Romero, M. D., Montes, M. J., Sin, E., López-Braña, I., Duce, A., MartínSánchez, J. A., Andrés, M. F., and Delibes, A. 1998. A cereal cyst nematode (Heterodera avenae Woll.) resistance gene transferred from Aegilops triuncialis to hexaploid wheat. Theor. Appl. Genet. 96:11351140 .

Ros Barcelo, A. 1995. Peroxidase and not laccase is the enzyme responsible for cell wall lignification in the secondary thickening of xylem vessels in Lupinus. Protoplasma 186:41-44.

Safari, E., Gororo N. N., Eastwood, R. F., Lewis, J., Eagles H. A., and Ogbonnaya, F. C. 2005. Impact of Cre $1, \mathrm{Cre} 8$ and $\mathrm{Cre} 3$ genes on cereal cyst nematode resistance in wheat. Theor. Appl. Genet. 110:567-572.

Schweizer, P. 2008. Tissue-specific expression of a defense-related peroxidase in transgenic wheat potentiates cell death in pathogen-attacked leaf epidermis. Mol. Plant Pathol. 9:45-57.

Seah, S., Spielmeyer, W., Jahier, J., Sivasithamparam, K., and Lagudah, E. S., 2000. Resistance gene analogs within an introgressed chromosomal segment derived from Triticum ventricosum that confers resistance to nematode and rust pathogens in wheat. Mol. Plant-Microbe Interact. 13:334-341.

Tamura, K., Dudley, J., Nei, M., and Kumar, S. 2007. MEGA4: Molecular Evolutionary Genetics Analysis (MEGA) software version 4.0. Mol Biol. Evol. 24:1596-1599.

Taylor, B., and Powell, A. 1982. Isolation of plant DNA and RNA. Focus 4:4-6.

Thordal-Christensen, H., Brandt, J., Cho, B. H., Rasmussen, S. K. Gregersen, P., Smedegard, V., and Collinge, D. 1992. cDNA cloning and characterization of two barley peroxidase transcripts induced differentially by the powdery mildew fungus Erysiphe graminis. Physiol. Mol. Plant Pathol. 40:395-409.

Tognolli, M., Penel, C., Greppin, H., and Simon, P. 2002. Analysis and expression of the class-III peroxidase large gene family in Arabidopsis thaliana. Gene 288:129-138.

Waetzing, G., Sobczak, M., and Grundler, F. M. W. 1999. Localization of hydrogen peroxide during the defence response of Arabidopsis thaliana against the plant-parasitic nematode Heterodera glycines. Nematology 1:681-686.

Welinder, K. G. 1992. Plant peroxidases: structure-function relationships. In: Plant Peroxidases. C. Penel, T. Gaspar, and H. Greppin, eds. University of Geneva, Switzerland.

Welinder, K. G., Justesen, A. F., Kjærsgård, I. V. H., Rikke, B. J., Rasmussen, S. K., Jespersen, H. M., and Duroux, L.. 2002. Structural diversity and transcription of class III peroxidases from Arabidopsis thaliana. Eur. J. Biochem. 269:6063-6081.

Xue, J., and Rask, L. 1995. The unusual 5' splicing border GC is used in myrosinase genes of the Brassicaceae. Plant Mol. Biol. 29:167-171.

Zacheo, G., Bleve-Zacheo, T., and Melillo, M. T. 1997. Biochemistry of plant defence responses to nematode infection. Pages 201-213 in: Cellular and Molecular Aspects of Plant-Nematode Interactions. C. Fenoll, F. M. W. Grundler, and S. A. Ohl, eds. Kluwer, Dordrecht, The Netherlands.

Zhao, J., Davis, L. C., Verpoorte, R. 2005. Elicitor signal transduction leading to production of plant secondary metabolites. Biotechnol. Adv. 23:283-333

Zhao, S., and Fernald, R. D. 2005. Comprehensive Algorithm for Quantitative Real-Time Polymerase Chain Reaction. J. Comp. Biol. 12:1047-1064. 